\title{
Problems in the Implementation of the Lean Concept at a Steel Works - Case Study
}

\author{
Adrian Maszke ${ }^{1, *}$, Renata Dwornicka ${ }^{2}$, and Robert Ulewicz ${ }^{3}$ \\ ${ }^{1}$ ArcelorMittal Warsaw, Poland \\ ${ }^{2}$ Cracow University of Technology, Poland \\ ${ }^{3}$ Czestochowa University of Technology, Poland
}

\begin{abstract}
The paper presents the experience of implementing selected instruments of the Lean concept at a steel works. The functioning of an enterprises in the currently prevailing conditions, i.e. in a turbulent environment, results in increased customer requirements. They expect, among other things, high quality of steel products delivered on time at a low price. Many organizations decide to implement the lean management concept without proper preparation. The purpose of this paper is to present the limitations occurring during the implementation of the lean management concept in a steel mill.
\end{abstract}

\section{Introduction}

Changes are a natural process occurring in each enterprise. They may be related to the transformation of the so-called "hard" components, e.g. technological changes, shop-floor workflow, purchasing of new technical equipment on the one hand, and the so called "soft" aspects, i.e. changes in the staff's attitudes or behaviour patterns on the other. In either case, one of the key factors behind successful implementation of the lean concept arepeople [1,3]. Lean management is a Japanese concept comprising management methods and techniques including: waste elimination, process mapping, 5S, Just in Time, kanban, Single Minute Exchange of Die, Total Productive Maintenance, One Piece Flow, work standardization and Total Quality Management [4-8].

By implementing the lean management concept, an enterprise triggers a transformation of both the intangible and the tangible - technological aspects. Such transformation is expected to allow an enterprise, a steel works in this case, to attain a flexibility allowing it to quickly adapt to the turbulent environment and a springiness helping it to quickly react to changes [9-11]. The idea behind the lean concept is, among other things, to reduce the number of changes-corrections, eliminate the warehouse space, improve the work flow, lower the manufacturing costs (by reducing the stoppage time and increasing the general efficiency of using machines and devices) [12-19]. Unfortunately, the anticipated effects of the concept can be attained only on the condition that one avoids the mistakes that frequently result from oversight, neglect or simply lack of knowledge. Therefore, it is

\footnotetext{
* Corresponding author: a.maszke@ado-odblaski.pl
} 
important to bring the mistakes occurring in the implementation of the lean concept to attention so as to avoid them [20-24].

\section{Lean Concept at a steel works}

The underlying activity of steel plant is the manufacture of liquid steel in different furnaces using different sources of heat necessary to carry out the production process and to further process steel in other departments. Currently, the Polish steel industry is controlled, among others, by the following companies: Arcelor Mittal, Cesla Huta Ostrowiec, CMC Zawiercie, ISD - Huta Częstochowa and Polish Steelworks.

These companies compete with each other, among other things, with respect to the technical manufacturing costs. The global competition significantly affects the headcount (social factor). One of the ways allowing to reduce the technical manufacturing costs is to implement the lean management concept to continually reduce losses. The starting point for a loss analysis should be the identification of the actual losses followed by determination of their causes, place and frequency of occurrence. The most important stage of the analysis is defining the present situation. Only then can improvements be proposed and verified. Elimination of waste is frequently impossible, so even its smallest reduction is a big achievement.

Each production process can be improved, and aiming at optimizing production by seeking any possible savings is the best illustration of that. No manufacturer tolerates any form of waste. Nowadays, however, this approach results in the production process being subjected to an in-depth analysis of its individual stages, especially with respect to the relevance and correctness of the current material and information flow of the customer service. This approach gives a company a unique opportunity to eliminate all redundant stages from the production process or to improve those which must not be eliminated due to their technological importance. In addition, each stage should be analysed in terms of its effectiveness to allow a company to produce only those products which can be used in a subsequent process (operation) as during these processes companies encounter barriers and limitations hampering proper implementation of the methods and techniques of lean management. According to research, the difficulty in implementing the lean concept results from the lack of identification with the company, its problems and needs, implementation of large, individual projects without following a long-term implementation plan, while ignoring the idea of continuous improvement, very high financial goals and expectations related to the lean department, the streams functioning as separate "companies within a company" and not as effect centres only, as well as from the lack of exchange of knowledge, ideas and information between the streams. An additional problem that frequently appears during the implementation is a lack of understanding of the Lean Concept by the entire management staff. Very often implementation of the concept is limited to the production area, which is perceived as an isolated element of the company. In the case of the analysed company, which is a part of a holding company, the key is to achieve financial objectives related to the lean department.

\section{Case study}

Implementation of the lean concept instruments is determined by attaining the anticipated financial goals by working toward optimizing the production by seeking potential savings. The problem to solve was to put individual costs into cost groups to facilitate the analysis and reduce waste, as no manufacturer tolerates any form of it. 
Similar flow streams are applied at production departments of a given steel plant, such as the melt shop or the rolling mill. The melt shop uses a Danarc electric furnace to melt steel, which is subsequently cast in the continuous casting process known as COS and then put into ingot moulds at the ingots line. Production departments such as the melt shop or the rolling mill are primarily responsible for handling the production and control processes specified in process sheets and instructions in conformity with the customer's requirements, as well as the legal and environmental regulations to minimize their environmental impact. Another important element is regular recording, analysing and storing of data related to production, inspection of the products manufactured and monitoring of the environmental impact. Another important element of control of each department is ensuring identification and traceability of products, including non-compliant products, packing of semi-finished and finished products without causing damage to them, as well as analysing the causes behind significant, repeated, existing or potential discrepancies and determining corrective or pre-emptive actions necessary to remove such discrepancies to be taken in cooperation with the Quality Control Department. Fig. 1 presents elements of the value stream of the melt shop department. It is that part of the theory and practice of metallurgy which deals with the manufacture of steel in electrical furnaces and is referred to as electrometallurgy.

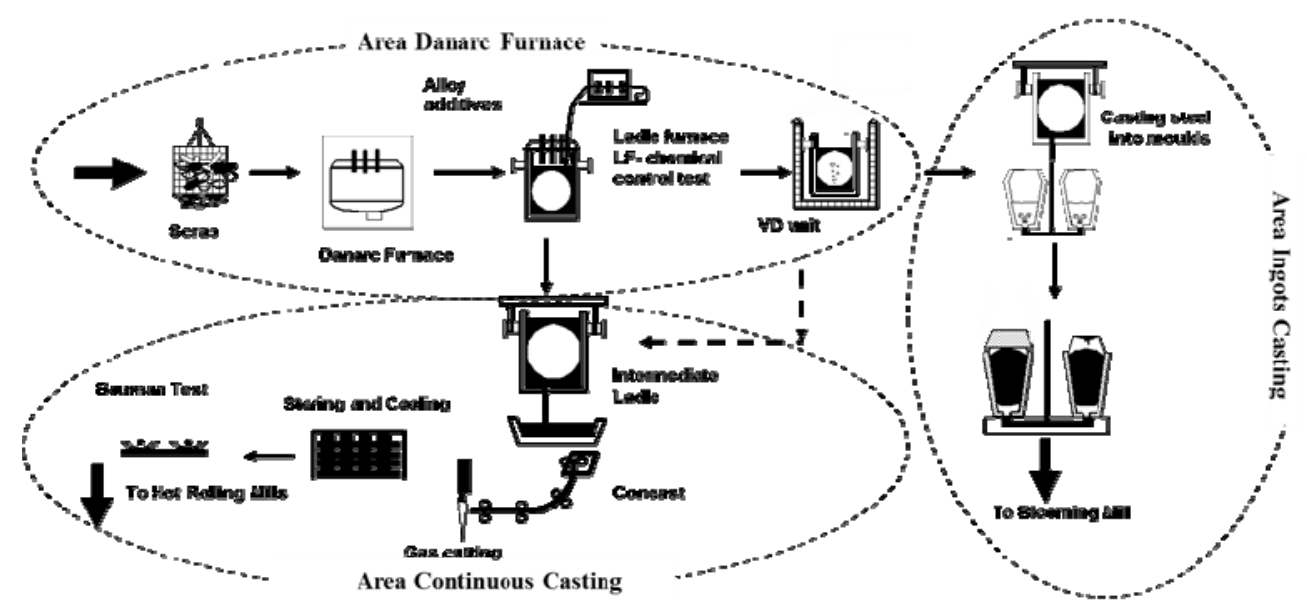

Fig. 1. Elements of the value stream at the melt shop department.

As the number of competitors who effectively use the direct labour force and machines increases, in addition to technical or process information, the management needs access to information about the costs of the production processes, products and customer service, such information being more precise than that obtained by means of the system used for the purposes of external financial statements. The simplest cost division is their division by resource type. All costs generated in the company in question are grouped by type of resource used and put into six groups of usage factors: C - charge factors, E - energy factors, M - material factors, S - service factors, L - Labour group factors, C2 - department common costs. Such cost division will allow to evaluate the effectiveness of the wasteeliminating activities or pro-lean activities introduced.

A preliminary research conducted to identify the obstacles in the implementation of the lean concept at the steel works indicated the following issues:

- lack of foundations for implementation of the lean concept. The organization does not have the so-called change and continuous improvement culture. Lack of teamwork ability. The employees seem not to identify with the company, its problems and needs. Another obstacle is the lack of conditions (lack of soft lean tools) to implement hard 
lean tools, such as standardization, TPM or 5S. Lack of employee's understanding of the lean concept.

- Focus on short-term projects without introducing long-term organizational changes. Implementation of individual, short-term projects without a long-term lean implementation plan while ignoring the idea behind continuous improvement.

- Financial requirements. The lean department is expected to keep cutting the operating expenses, as a result of which the lean processes are associated with reducing the headcount and total distrust of employees responsible for the implementation of the lean concept.

- Division of a company into streams. Streams function as separate enterprises within a company, rather than effect centres. Streams compete rather than cooperate with each other. This hampers exchange of information between particular streams and makes the company look more like a functional rather than a process-oriented enterprise.

- Procedures The procedures and instructions applied by the company are too complex and hamper work. Collecting data that is not analysed or difficult to interpret.

- Trainings. Lack of specific materials to be used during trainings and a failure to enforce implementation of particular stages of the lean concept. Lack of indicators for implementation of the lean concept.

- Unavailability of reliable data. Many lean projects have been conducted without a detailed observation and analyses, mostly based on a process-related documentation.

At the steelworks in question, the lean activities are evaluated based on cost groups by type of the resource used. In this study, the direct costs will be the following groups: C charge factors, M - material factors, S - service factors, R-labour factors. Although they belong in the direct costs category, the charge factors (W) will be handled separately as an input cost as they constitute the biggest component. Both the costs and the production volume are time-related. Therefore, any production level must be determined relative to some general, average period of time. More importantly, the costs incurred by a company change in time. They may change both in a short and long term. Short-term costs may be fixed or variable. The total fixed cost (TFC) remains at the same level irrespective of whether a plant is working at full capacity or not working at all. As long as an enterprise has even a single fixed cost item, it operates over a short term. The total variable costs (TVC) increase together with the production costs. The total fixed cost and the total variable costs together yield the total cost. The total cost (TC) constitutes the sum of the fixed and variable costs at each production level. Following the classic cost division, each enterprise introduces small changes depending on its nature in order to best present its costs and provide information about them. The above-mentioned implemented system has resulted in an improved control over particular groups of cost factors. The system has contributed to a faster analysis of particular cost groups and details of a given group, which previously caused a lot of problems and required more time to identify a waste area.

\section{Discussion and conclusions}

Application of the cost-based approach in the analysis of effectiveness of lean activities has allowed the steelworks in question to:

- apply a quick and effective analysis in given cost groups,

- make faster decisions regarding areas needing improvement,

- reduce the consumption of utilities and auxiliary materials,

- shorten the calculation cycles for particular usage groups,

- improve the economic results. 
At the stage of collecting the data relating to particular cost factors no problems were identified which could stop an already commenced grouping process, but only a discussion was noticed related to the location of particular cost groups. The applied model of division of costs into cost groups such as C - charge, E - energy factor, M - material factors, Sservice factors, L-labour factors and K-2 common factors seems to be working and is verified on a monthly basis following balancing of data to verify its weaknesses and strengths. Each month a cost meeting is held with the team of a given department in order to carry out a costs analysis to be later reported to the management. Table 1 presents the percentage share of particular determinants of cost groups at the melt shop without taking into account the waste for particular sub-department such as: LSS - Liquid Steel Shop - the EAF furnace area, CCS - Continuous Casting Shop and CLS - Cast Line Shop - the ingots area.

Table 1. Percentage share of determinants of cost groups at the melt shop without taking into account waste.

\begin{tabular}{|r|l|c|c|c|}
\hline & & LSS & CCS & CLS \\
\hline C & Charge factors & 79.89 & 95.21 & 91.93 \\
\hline E & Energy factors & 11.03 & 0.89 & 0.55 \\
\hline $\mathrm{M}$ & Material factors & 6.10 & 2.14 & 3.93 \\
\hline S & Service factors & 1.52 & 0.92 & 1.10 \\
\hline TVC & variable costs & $\mathbf{9 8 . 5 4}$ & $\mathbf{9 9 . 1 6}$ & $\mathbf{9 7 . 5 1}$ \\
\hline L & labour factors & 0.68 & 0.37 & 1.29 \\
\hline K2 & common costs & 0.78 & 0.47 & 1.20 \\
\hline TFC & fixed cost & $\mathbf{1 . 4 6}$ & $\mathbf{0 . 8 4}$ & $\mathbf{2 . 4 9}$ \\
\hline TC & total cost & $\mathbf{1 0 0 . 0}$ & $\mathbf{1 0 0 . 0}$ & $\mathbf{1 0 0 . 0}$ \\
\hline
\end{tabular}

The results of a preliminary research of the value streams management as one of the elements of the lean concept indicates that the obstacle encountered at the steelworks in question is the culture of the organization in terms of implementing the lean instruments. A survey conducted among the shop floor staff and the managers shows that the most common problems include: a barrier in the contacts between the management and the employees, lack of standardization, short-term financial goals, referred to as short-termism, lack of information about the effects of activities and associating lean with headcount reduction. It should be pointed out, though, that application of the cost-based approach as an evaluation of the functioning of line activities in the company in question has yielded positive results.

Table 2. Waste in percentage at the melt shop for TC, TVC, TFC and particular determinant of cost groups for three production areas.

\begin{tabular}{|r|l|c|c|c|}
\hline & LSS & CCS & CLS \\
\hline $\begin{array}{r}\text { Average monthly production } \\
\text { (tonnes) }\end{array}$ & 43,371 & 33,643 & 7,805 \\
\hline C & Charge factors & 2.76 & 2.67 & 4.60 \\
\hline $\mathrm{E}$ & Energy factors & 2.87 & 5.54 & 17.75 \\
\hline $\mathrm{M}$ & Material factors & 2.01 & 6.42 & 14.17 \\
\hline $\mathrm{U}$ & Service factors & 12.70 & 19.59 & 14.63 \\
\hline TVC & variable costs & $\mathbf{2 . 5 5}$ & $\mathbf{2 . 7 5}$ & $\mathbf{4 . 3 0}$ \\
\hline $\mathrm{R}$ & labour factors & 8.44 & 6.62 & 16.58 \\
\hline K2 & common costs & 9.80 & 9.79 & 16.92 \\
\hline TFC & fixed cost & $\mathbf{8 . 0 6}$ & $\mathbf{6 . 7 3}$ & $\mathbf{1 3 . 2 4}$ \\
\hline TC & total cost & $\mathbf{2 . 5 9}$ & $\mathbf{2 . 7 4}$ & $\mathbf{4 . 4 1}$ \\
\hline
\end{tabular}


The impact of the waste costs factors on the company's economic result is complex in terms of the structure of the production and costs, while the presented results should be helpful in finding the optimal solution in the lean activities. The presented model functions in the company in question, however, an area has been identified that needs improvement in terms of a better tailored division of costs for an easier analysis.

\section{References}

1. W.L. Tate, L.M. Ellram, L. Bals, E. Hartmann, International Journal Production Economics, 120(2), 512-524 (2009)

2. T.R. Holcomb, M.A. Hitt, Journal Operations Management, 25(2), 464-481 (2007)

3. S. Wuyts, A. Rindfleisch, A. Citrin, Journal Operations Management, 35, 40-55 (2015)

4. L.M. Ellram, W.L. Tate, C. Billington, Journal Operations Management, 26(2), 148163 (2008)

5. J.M., Hallikas, I. Karvonen, U. Pulkkinen, VM. Virolainen, M. Tuominen, International Journal Production Econmics, 90(1), 47-58 (2004)

6. S.M. Handley, W.C. Jr. Benton, Journal Operations Management, 31(3) 109-128 (2013)

7. H. Kenneth, J.B. Wathne, Journal of Marketing, 64(4), 36-51 (2000)

8. S.M. Handley, J.V. Gray, Journal Operations Management, 22(6) 1540-1556 (2013)

9. S. Borkowski, K. Knop, Production Engineering Archives, 1, 25-28 (2013)

10. H. Golas, A. Mazur, P. Piasek, P. Czajkowski. Problemy Jakości, 2, 10-14, (2017)

11. K. Mielczarek, K. Knop, Production Engineering Archives, 13, 16-19 (2016)

12. K. Knop, K. Mielczarek, Technical Transactions Mechanics, 3, 67-72 (2016)

13. J. Selejdak, T. Corejova, R. Ulewicz, Total Quality Management (Wz-PCz, 2016)

14. C.G. Drury, M.A. Sinclair, Human Factors, 25, 391-399 (1983)

15. K. Stecuła, J. Brodny, SGEM 2016 Conference Proceedings, Book 1, 2, 57-64 (2016)

16. J. Brodny, K. Stecuła, M. Tutak:. SGEM 2016 Conference Proceedings, Book1, 2, 6572 (2016)

17. J. Brodny, S. Alszer, J. Krystek, M. Tutak, Archives of Control Sciences, 27(LXIII), 197-209 (2017)

18. J. Pietraszek, E. Skrzypczak-Pietraszek, Adv. Mat. Res.-Switz., 874, 151 (2014)

19. J. Pietraszek, A. Gądek-Moszczak, T. Torunski, Adv. Mat. Res.-Switz., 874, 139 (2014)

20. A. Czajkowska, R. Stasiak-Betlejewska, Metal 2016: $25^{\text {th }}$ Anniversary International Conference On Metallurgy And Materials, 1763-1768 (2016)

21. M. Potkany, R. Stasiak-Betlejewska, R. Kovac, M. Gajdos. Polish Journal Of Management Studies, 13(1), 145-156 (2016)

22. M. Ingaldi, S.T. Dziuba, Metal 2016: $25^{\text {th }}$ Anniversary International Conference On Metallurgy And Materials, 1822-1828 (2016)

23. R. Ulewicz, M. Nowicka-Skowron. 26 $6^{\text {th }}$ Anniversary International Conference On Metallurgy And Materials, 2338-2343 (2017)

24. M. Zasadzień, J. Zarnovsky, Management Systems In Production Engineering, 26(1), 55-59 (2018) 